\title{
Higher Education Leadership and Management Training
}

Global Maps and Gaps

\author{
Laura E. Rumbley, Hilligje van't Land and Juliette Becker
}

Successful leadership of higher education institutions in the contemporary context worldwide requires a remarkably sophisticated set of skills, knowledge, and sensibilities. Yet, globally, there is limited information about how higher education's leaders, managers, and policymakers are provided with the training they need to carry out their work. Furthermore, where information about such training and capacity-building programs is available, the picture remains incomplete and often disheartening. In fact, the structured opportunities on offer to build leadership and management capacity in higher education are limited in number, almost universally small in scale, and largely unable to offer systematic accounts of the long-term impact of their efforts. This is a critical concern in the face of the myriad opportunities and imperatives facing higher education institutions and systems around the world, now and into the foreseeable future. Without question, the vast majority of higher education leaders and managers enter their positions with no training whatsoever - they learn "on the job" — or run the risk of failure.

Two recent studies - one by the Boston College Center for International Higher Education (CIHE), on behalf of the German Academic Exchange Service (DAAD) and German Rectors' Conference (HRK), and another by the International Association of Universities (IAU) on behalf of the World Bank-have mapped various dimensions of the global landscape of higher education management and leadership training programs. In the case of IAU, the goal was to identify training programs around the world focused specifically on leadership (typically in mid- and senior-level administrative positions) in higher education. CIHE's purpose was slightly different, given its aim to make sense of major players offering management training schemes specifically in relation 
to international development cooperation efforts (i.e., for capacity building in lower-income and emerging country contexts).

In exploring the existence and profiles of such training schemes worldwide, both IAU and CIHE discovered that very little work has been done to date to take stock of these types of programs at a global level. Extensive networking and dogged online research were required to identify programs, and to piece together fundamental characteristics of training program size, scope, design, delivery, evolution, and aims. Unlike postgraduate degree-granting programs focused on different aspects of higher education, which are typically offered by single universities (or clearly defined university partners), training programs geared toward high.er education professionals may be delivered by a wide range of providers. Some are also characterized by what might be considered a chain of providers, whereby different actors are separately responsible for funding, managing/organizing, and/or delivering specific training programs. To date, there is no clear "typology" for the global field of higher education management, training providers, or approaches.

There is significant diversity in the way that training programs approach their work. This diversity is apparent across such dimensions as the ages of programs, the sizes of their cohorts, the frequency with which program iterations are offered, the target audiences they aim to serve, the "pedagogical approaches" they employ, the length of programs, and the topics on which programs focus, among other key characteristics.

This diversity presents an interesting panorama across the global training landscape. Programs range in age from decades old to the very recently launched. In terms of target groups, they may cater to senior leadership or middle- and upper-middle level managers and administrators, or to specially identified populations, such as promising early-career individuals, administrators with specifically defined roles and responsibilities, or members of underrepresented groups, such as women.

Program modes of delivery may involve workshops, conferences, seminars, lectures, case studies, site visits, internships, group projects, personal projects, or independent research. Training schemes may even be anchored in longterm institutional partnerships, as seen particularly in some European initiatives focused on international cooperation for development. Trainings may feature face-to-face and/or online delivery. 
The frequency and duration of trainings may also vary from a matter of days or weeks, or-more unusually - to months, and even a year or longer. Some programs consist of quite standardized "off the shelf" offerings in terms of structure and content, while others may be more specifically tailored to client or participant needs. There is, quite literally, a world of possibility when it comes to training content, approaches, target audiences, and rationale.

\section{3}

\section{Emerging Contours in a World of Variety}

Although training programs in higher education worldwide display significant variation in their form and function, several key trends are apparent from the data now available about these schemes.

First, the training of higher education leaders and managers stands out as a "growth industry" globally. This is indicated by the significant numbers of training programs and schemes that have been initiated in the period since 200o. Notably, however, higher education training and leadership development programs are predominately on offer in the world's wealthier countries, or are delivered (or otherwise made possible) by providers, funders, and/or partners who largely hail from the Global North.

Where data exist, we see that most programs feature small numbers of participants, often under 50 per group. Additionally, cohorts tend to be rather "homogenous," in the sense that they tend not to include different kinds of participants in the same training groups (for example, at different levels of seniority). Little evidence exists that much special attention is being paid to the training or leadership skill cultivation of women in higher education, despite their significant representation in student enrollment and (at least early stage) faculty ranks globally.

Training programs are also relatively short in duration, most often ranging from several days to one or two weeks. They are typically fee based and do not tend to award any kind of credential, beyond merely documenting attendance. Finally, there is very little indication that training programs are undertaking the kinds of assessment activities that yield clear evidence of their mid-term outcomes or longer-term impact. Often, assessment rests on the testimonials of beneficiaries or the organizations offering the training courses, without providing information on the monitoring tools developed to measure the impact of these courses on participants or their respective professional environments. One of the most commonly cited impacts is the importance of the networking opportunities provided, a result that is difficult to translate into any kind of impact assessment. 


\section{$4 \quad$ Is More Needed? Yes}

The majority of higher education leaders and managers around the world receive no formal/specialized training for their work. As higher education systems continue to grow and diversify, increasingly pressured to meet key performance indicators while also achieving excellence in education and innovation production, the need to train effective managers and leaders becomes more widespread and more urgent. Yet, the current picture of training opportunities on offer to meet this massive need falls desperately short. Indeed, the CIHE and IAU inventory exercises, albeit tailored to seek out some kinds of programs and not others, collectively identified fewer than 120 such training schemes worldwide. Relatively short, small-scale programs, clustered in (or provided largely by actors based in) the Global North, operating without clear evidence of midor long-term impact — collectively, these do not provide a viable roadmap for the kind of large-scale support needed by higher education systems, particularly in the world's low-income and emerging economy countries. There, the needs are urgent to scale up management and leadership capacity through the provision of high-quality, relevant, and equity-enhancing training mechanisms. Significantly more research is needed to make sense of the full census of management and leadership training actors around the world, as well as the scope and real-world impact of their efforts, in order to ensure the deployment of skilled higher education managers and leaders for the twenty-first century.

\section{Acknowledgement}

This chapter was previously published in International Higher Education, No. 93, Spring 2018 (pp. 4-6). Reprinted here with permission. 